\title{
Effects of Nanoclay and Glass Fiber on the Microstructural, Mechanical, Thermal, and Water Absorption Properties of Recycled WPCs ${ }^{1}$
}

\author{
Young-Rok $\mathrm{Seo}^{2} \cdot$ Birm-June Kim $\mathbb{D}^{2, \dagger} \cdot$ Sun-Young $\mathrm{Lee}^{3}$
}

\begin{abstract}
When wood plastic composites (WPCs) have been used for a certain period of time, they become waste materials and should be recycled to reduce their environmental impact. Waste WPCs can be transformed into reinforced composites, in which fillers are used to improve their performance. In this study, recycled WPCs were prepared using different proportions of waste WPCs, nanoclay, and glass fiber. The effects of nanoclay and glass fiber on the microstructural, mechanical, thermal, and water absorption properties of the recycled WPCs were investigated. X-ray diffraction showed that the nanoclay intercalates in the WPCs. Additionally, scanning electron micrographs revealed that the glass fiber is adequately dispersed. According to the analysis of mechanical properties, the simultaneous incorporation of nanoclay and glass fiber improved both tensile and flexural strengths. However, as the amount of fillers increases, their dispersion becomes limited and the tensile and flexural modulus were not further improved. The synergistic effect of nanoclay and glass fiber in recycled WPCs enhanced the thermal stability and crystallinity $\left(\mathrm{X}_{\mathrm{c}}\right)$. Also, the presence of nanoclay improved the water absorption properties. The results suggested that recycled WPCs reinforced with nanoclay and glass fiber improved the deteriorated performance, showing the potential of recycled waste WPCs.
\end{abstract}

Keywords: wood plastic composites, waste materials, recycled composites, nanoclay, glass fiber

\section{INTRODUCTION}

Wood Plastic Composites (WPCs) are composite materials mainly composed of wood flour and thermoplastic polymers. While wood flour has the advantages of low cost, low density, and biodegradability, thermoplastic polymers have good moisture resistance and di- mensional stability. Since WPCs showed the advantages of both wood and thermoplastic materials, WPCs have been applied to housings where wood and thermoplastic materials are needed as alternatives of conventional construction materials (deck, fence, siding and window frame, etc.). Recently, in furniture and automotive industries, the use of WPCs has been steadily increasing

\footnotetext{
${ }^{1}$ Date Received April 2, 2019, Date Accepted July 15, 2019

2 Department of Forest Products and Biotechnology, Kookmin University, Seoul 02707, Republic of Korea

${ }^{3}$ Wood Chemistry Division, National Institute of Forest Science, Seoul 02455, Republic of Korea

† Corresponding author: Birm-June Kim (e-mail: bjkim3@kookmin.ac.kr, ORCID: 0000-0001-6720-4479)
} 
Effects of Nanoclay and Glass Fiber on the Microstructural, Mechanical, Thermal, and Water Absorption Properties of Recycled WPCs

(Ashori, 2008; Kim, 2014; Gardner et al., 2015).

Nanoclay consists of nano-sheets called layered silicates. Thus, it has been used as a nano reinforcing filler for various composites. Pinnavaia et al. found that the proper intercalation and exfoliation of nanoclay led to improved performance by causing full dispersion in composite matrix (Pinnavaia et al., 2000). Also, Hemmasi et al. reported that WPCs reinforced with nanoclay showed improved flexural and tensile moduli (Hemmasi et al., 2010). Besides, Deka and colleagues suggested that the incorporation of nanoclay into thermoplastic polymer mixture (HDPE, LDPE, PP, and PVC) improved mechanical, thermal, and water absorption properties (Deka et al., 2010).

Glass fiber is the most commonly utilized fiber material in automobile and aerospace industries due to high strength and light weight properties (Rahman et al., 2012). For this reason, it has been also used as a good reinforcing filler for WPCs. Jiang et al. showed that PVC/wood flour composites reinforced with long glass fiber improved impact and flexural properties (Jiang et al., 2003). Moreover, Rizvi et al. reported that the incorporation of glass fiber into WPCs improved both strength and modulus (Rizvi et al., 2008). Also, improved flexural properties were shown in glass fiber reinforced wood-based composites (Zhang and Ma, 2016).

As the use of WPCs has increased, studies to reduce the environmental impacts by WPCs was considered, so, there have been many attempts to manufacture WPCs by recycling waste wood and thermoplastic waste resources. Najafi et al. showed that WPCs manufactured by mixing recycled-HDPE/PP and virgin-HDPE/PP improved the deteriorated mechanical properties (Najafi et al., 2006). Two years later, Adhikary et al. reported that the incorporation of coupling agent led to the improvement of mechanical properties and water absorption stability of WPCs fabricated with recycled HDPE and sawdust (Adhikary et al., 2008). Also, Chaharmahli et al. suggested that WPCs manufactured with recycling waste MDF or waste particle board (PB) showed the actual recycling potential of used wood wastes (Chaharmahli et al., 2008). More recently, Hyvarinen et al. stated that WPCs filled with wood and plastic wastes from the construction and demolition industries improved water absorption and thickness swelling properties (Hyvarinen et al., 2019). However, there is little experimental research on recycled WPCs using waste WPCs.

Waste WPCs, which have been used for a certain period of time, are considered as wastes in everyday life, and should be recycled to reduce the environmental impacts. Since waste materials have deteriorated performances, it is necessary to improve the performances by manufacturing reinforced composites using various fillers. Nanoclay imparts balanced performances to filled composites by controlling dispersibility even if only a small amount is used. Glass fiber is preferred as a reinforcing filler because it has low cost, easy processibility, and high aspect ratio. Recently, synergistic effects have been achieved by incorporating nanoparticles into the matrix of fiber-reinforced composites. These hybrid composites show high strength and modulus, decreased gas or liquid permeability, and reduced flammability with competitive costs (Rahman et al., 2012). The waste WPCs after used for a certain period of time have originally deteriorated performances and they need to be recycled as hybrid composites reinforced with various fillers. The aim of this study is to investigate the effect of nanoclay and glass fiber on the microstructural, mechanical, thermal, and water absorption properties of recycled ternary hybrid composites (i.e., recycled WPCs) based on waste WPCs.

\section{MATERIALS and METHODS}

\subsection{Materials}

Waste WPC used in this study was provided by WPC manufacturer (Korea), which consists of wood flour, 


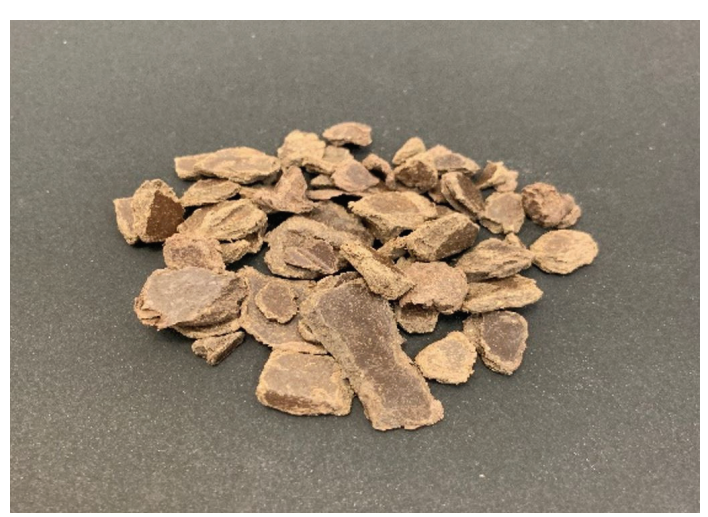

Fig. 1. Waste WPC with crushed form.

polypropylene, polyethylene, talc, UV stabilizer and others (Fig. 1). But, accurate information on the composition ratio of each element was not provided. Waste WPC with crushed form was finely ground, and then dried at a temperature of $60^{\circ} \mathrm{C}$ for 4 days before compounding. Nanoclay was provided by Nanocor Co., Ltd. (USA) as a master batch (nanoMax-PP) including 50 wt.\% of nanoclay, 25 wt.\% of polypropylene, and 25 wt.\% of maleic anhydride grafted polypropylene. Glass fiber also was purchased from Lotte Chemical Co., Ltd. (Korea) in a master batch containing 50 wt.\% of glass fiber and 50 wt.\% of polypropylene. The average length of glass fiber was around $10 \mathrm{~mm}$, and the fiber surface was sizing-treated.

\subsection{Methods}

\subsubsection{Preparation of composites}

Waste WPC was melt-compounded using a BA-19 co-rotating twin screw extruder (Bautek Co., Ltd, S. Korea) with $\mathrm{L} / \mathrm{D}$ ratio of 40 and eight temperature zones. The barrel temperature zones of the extruder were 185, $190,195,190,185,180,170$ and $120^{\circ} \mathrm{C}$, respectively. The screw speed was set at $60 \mathrm{rpm}$ to minimize the breakage of glass fiber during compounding process. The compounded composites were pelletized using a BA-PLT pelletizer (Bautek Co., Ltd, Korea). The
Table 1. Formulations ratios of various recycled WPCs

\begin{tabular}{lccc}
\hline \multirow{2}{*}{ Specimen } & \multicolumn{3}{c}{$\begin{array}{c}\text { Composition based on } \\
\text { weight (wt.\%) }\end{array}$} \\
\cline { 2 - 4 } & W-WPC & NC & GFC \\
\hline W-WPC100 & 100 & - & - \\
W-WPC95/NC5 & 95 & 5 & - \\
W-WPC90/NC10 & 90 & 10 & - \\
W-WPC85/NC15 & 85 & 15 & - \\
\hline W-WPC80/GFC20 & 80 & - & 20 \\
W-WPC75/NC5/GFC20 & 75 & 5 & 20 \\
W-WPC70/NC10/GFC20 & 70 & 10 & 20 \\
W-WPC65/NC15/GFC20 & 65 & 15 & 20 \\
\hline W-WPC60/GFC40 & 60 & - & 40 \\
W-WPC55/NC5/GFC40 & 55 & 5 & 40 \\
W-WPC50/NC10/GFC40 & 50 & 10 & 40 \\
W-WPC45/NC15/GFC40 & 45 & 15 & 40 \\
\hline W-WPC40/GFC60 & 40 & - & 60 \\
W-WPC35/NC5/GFC60 & 35 & 5 & 60 \\
W-WPC30/NC10/GFC60 & 30 & 10 & 60 \\
W-WPC25/NC15/GFC60 & 25 & 15 & 60 \\
\hline GFC100 & - & - & 100 \\
\hline
\end{tabular}

manufactured pellets were then fed into a BOY 12M injection molding machine (Dr. Boy GmbH \& Co. KG, Germany) to produce recycled WPC specimens. The barrel temperature zones of the injection molding machine was $190,185,175$ and $120^{\circ} \mathrm{C}$, respectively. Total 17 types of recycled WPC specimens were prepared in different formulation ratios of nanoclay, glass fiber, and waste WPC. The formulation ratios of the recycled WPCs are shown in Table 1.

\subsubsection{Characterization of composites}

The intercalation of nanoclay in the composites was characterized by X-ray diffraction (XRD). For XRD analysis, Ultima IV (Rigaku, Japan) with $\mathrm{Cu} \mathrm{K} \alpha$ radiation ( $\lambda=0.154 \mathrm{~nm}, 40 \mathrm{kV}, 40 \mathrm{~mA}$ ) at a scanning rate of $3^{\circ} / \mathrm{min}$ with an angle ranging from $3^{\circ}$ to $15^{\circ}$ was used. Based on Bragg's law [Eq. (1)], the spacing of the layered nanoclay platelets was determined from 
Effects of Nanoclay and Glass Fiber on the Microstructural, Mechanical, Thermal, and Water Absorption Properties of Recycled WPCs

the $2 \theta$ position of diffraction peak of the clay.

$$
\mathrm{n} \lambda=2 \mathrm{~d} \sin \theta
$$

where $\mathrm{n}$ is the interger number of wavelength $(\mathrm{n}=$ $1) ; \lambda$ is the wavelength of the X-rays; $d$ is the interlayer spacing of the clay in the composite; $\theta$ is half of the angle of diffraction.

The fractured surfaces of impact tested specimens were observed using a JSM-7610F (Jeol Ltd., Japan) field emission scanning electron microscope (FE-SEM). Specimens were platinum-coated and then analyzed at an acceleration voltage of $5 \mathrm{kV}$.

\subsubsection{Mechanical tests of composites}

Tensile and flexural strength tests were carried out using universal testing machine (Zwick Testing Machine Ltd., UK) in accordance with ASTM D638 and ASTM D790, respectively. The test speed was set at $10 \mathrm{~mm} / \mathrm{min}$. Izod impact strength test was performed using a DTI-602B digital impact test machine (DaeKyung Technology, Korea) accordingly to ASTM D256. Test results were obtained from the average of the measurements of five specimens.

\subsubsection{Thermal analysis of composites}

Thermogravimetric analysis (TGA) was carried out using a SDT-Q600 thermogravimetirc analyzer (TA instrument, USA) to investigate the thermal decomposition temperature of recycled WPC specimens. The specimens were heated from $30^{\circ} \mathrm{C}$ to $650^{\circ} \mathrm{C}$ at a heating rate of $10^{\circ} \mathrm{C} / \mathrm{min}$ in nitrogen (N2) atmosphere. About $20 \mathrm{mg}$ of extruded pellets were used for the TGA analysis. Differential scanning calorimetry (DSC) analysis was performed using a DSC Q10 differential scanning calorimeter (TA instrument, USA) to study the thermal behavior of the recycled WPC specimens. The specimens were heated from $30^{\circ} \mathrm{C}$ to $250^{\circ} \mathrm{C}$ at a heating rate of $10^{\circ} \mathrm{C} / \mathrm{min}$, and then after holding for
$1 \mathrm{~min}$, it was swept back at a cooling rate of $-10^{\circ} \mathrm{C} / \mathrm{min}$. About $10 \mathrm{mg}$ of extruded pellets were used for the DSC analysis. Glass transition temperature $\left(\mathrm{T}_{\mathrm{g}}\right)$, melting temperature $\left(\mathrm{T}_{\mathrm{m}}\right)$, cold crystallization temperature $\left(\mathrm{T}_{\mathrm{c}}\right)$, and degree of crystallinity $\left(\mathrm{X}_{\mathrm{c}}\right)$ were determined by DSC analysis. The crystallinity of the composites was calculated using [Eq. (2)]:

$$
X_{\mathrm{c}}(\%)=\triangle \mathrm{H}_{\mathrm{m}} / \triangle \mathrm{H}_{100 \%} \times 100 \quad \cdots \cdots \cdots(2)
$$

where $X_{c}$ is degree of crystallinity; $\triangle H_{m}$ is the melting enthalpy of the composite; $\triangle \mathrm{H}_{100 \%}$ is the melting enthalpy of pure polypropylene (138 J/g).

\subsubsection{Water absorption tests of composites}

Water absorption tests were performed accordingly to ASTM D570. For each formulation, five specimens were immersed in distilled water at room temperature for 10 weeks. The weight and thickness of the specimens were periodically measured after removing moisture from the surface of the immersed specimens. After the measurement, the specimens were immersed again in distilled water for next tests. The water absorption and thickness swelling were calculated using [Eq. (3), (4)]:

$$
\begin{aligned}
& \text { Water Absorption (\%) } \\
& =\left(\mathrm{W}_{\text {wet }}-\mathrm{W}_{\mathrm{i}}\right) / \mathrm{W}_{\mathrm{i}} \times 100 \\
& =\left(\mathrm{T}_{\text {wet }}-\mathrm{T}_{\mathrm{i}}\right) / \mathrm{T}_{\mathrm{i}} \times 100
\end{aligned}
$$
immersion. 


\section{RESULTS and DISCUSSION}

\subsection{Microstructural properties}

XRD patterns of various recycled WPCs are observed in Fig. 2, and the XRD data are summarized in Table 2. XRD analysis confirmed the presence and the intercalation degree of nanoclay in the nanoclay filled composites (Kanny et al., 2008). Nanoclay filled composites showed similar XRD peaks and these indicated the existence of nanoclay in composites. However, the intensity and width of the diffraction peak were increased when the nanoclay was additionally incorporated into the composite matrix. This suggests that the increases in nanoclay content were related with more ordered structures and high aggregation ratios of

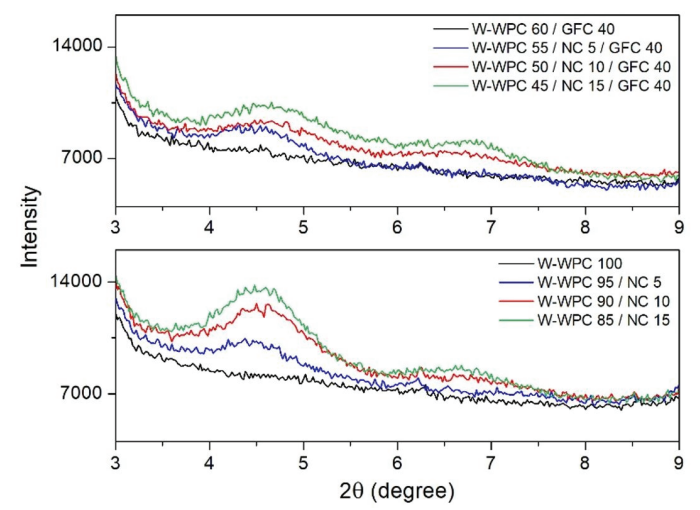

Fig. 2. XRD patterns of various recycled WPCs.

Table 2. XRD data of various recycled WPCs

\begin{tabular}{lcc}
\hline \multicolumn{1}{c}{ Specimen } & $\begin{array}{c}2 \theta \\
\text { (degree) }\end{array}$ & $\begin{array}{c}\text { d-spacing } \\
\text { (nm) }\end{array}$ \\
\hline \hline W-WPC95/NC5 & 4.38 & 2.01 \\
W-WPC90/NC10 & 4.5 & 1.96 \\
W-WPC85/NC15 & 4.48 & 1.97 \\
\hline W-WPC55/NC5/GFC40 & 4.32 & 2.04 \\
W-WPC50/NC10/GFC40 & 4.54 & 1.94 \\
W-WPC45/NC15/GFC40 & 4.66 & 1.89 \\
\hline
\end{tabular}

nanoclay (Rahman et al., 2012). The XRD patterns of the recycled WPCs filled with both nanoclay and glass fiber showed broader peaks compared to the composites without glass fiber. This probably indicates that nanoclay retains its original crystalline structure and shows a similar peak in the nanoclay filled composites, but it is partially exfoliated in the nanoclay/glass fiber filled composites due to the presence of glass fibers. The d-spacings decreased with increasing amount of nanoclay in composites with glass fibers. This suggests that the presence of glass fibers in the composite interferes with nanoclay exfoliation and induces aggregation leading to the absence or reduction in the characteristic peak intensity (Bozkurt et al., 2007).

The SEM images of various recycled WPCs are observed in Fig. 3. Fig. 3(a) shows the image of waste WPC only composite, showing good interfacial bonding between the wood flour and polymer matrix in the composite. Fig. 3(b) shows the image of the composite with 15wt.\% NC and 85wt.\% W-WPC. But, it was difficult to observe the nano-sized clays clearly in Fig. 3(b). Fig. 3(c) and Fig. 3(d) show the differences in glass fiber content. More glass fibers were observed in the composite with 60wt.\% GFC than in the composite with 20wt.\% GFC, and also many voids were found in the composite with 60wt.\% GFC due to fiber pull-outs. Fig. 3(e) shows the SEM image of composite with 60wt.\% GFC and 40wt.\% W-WPC, showing good interfacial bonding between polymer matrix and glass fiber. Fig. 3(f) shows the SEM micrograph of composite with 15wt.\% NC, 60wt.\% GFC, and 25wt.\% W-WPC. In this image, the interfacial bondings between glass fiber and polymer matrix were observed, but similar to Fig. 3(b), the nano-sized clays were difficult to observe through the fracture surface of the composites. Nanoclay was difficult to observe throughout SEM image, but could be supported by the XRD results mentioned above. 

and Water Absorption Properties of Recycled WPCs
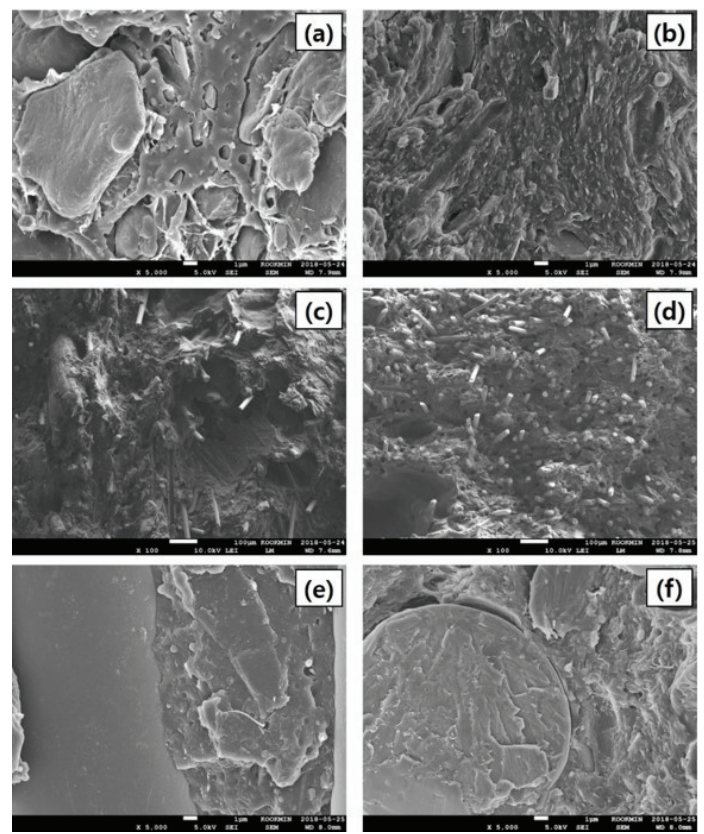

Fig. 3. SEM images of various recycled WPCs: (a) W-WPC100 $(\times 5000)($ b) W-WPC85/NC15 $(\times 5000)$ (c) W-WPC80/GFC20 $(\times$ 100) (d) W-WPC40/GFC60 $(\times 100)($ e) W-WPC40/GFC60 (× 5000) (f) W-WPC25/ NC15/GFC60 $(\times 5000)$.

\subsection{Mechanical properties}

Impact strengths of various recycled WPCs are observed in Fig. 4. The impact strength increased with the incorporation of glass fiber. Glass fibers are long fibers with high aspect ratio, which effectively absorb energy generated from external impact and disperse stress. Also, the surface sizing treatments of glass fibers normally improves the impact strength of filled composites by increasing the interfacial bonding between glass fiber and polymer matrix (Thomasson, 2002). The impact strength decreased with the incorporation of nanoclay. Nanoclay is a nano-sized filler having platelet shape and high aspect ratio. When intercalation and exfoliation occur properly in the composite, it is well dispersed and subsequent toughening effect improves the impact strength (Kim et al., 2008). However, since

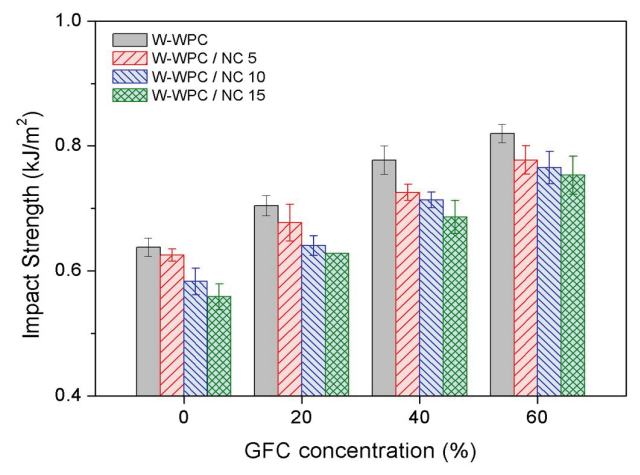

Fig. 4. Impact strength of various recycled WPCs.

the nanoclay filled in recycled WPCs is much smaller in size than wood flour and glass fiber, and it is difficult to show toughening effects. As the nanoclay content increases, clay aggregation occurs due to van der Waals force (Borse et al., 2009). In this case, exfoliation does not occur properly and fracture failure occurs due to poor dispersion (Hemmasi et al., 2010). Therefore, it is considered that the impact strength is decreased.

Tensile properties of various recycled WPCs are observed in Fig. 5. The incorporation of glass fiber and nanoclay in the composites improved the tensile strength. This is probably due to the increased orientation of glass fiber in longitudinal direction during the injection molding processing. The sizing treated glass fiber and the appropriately intercalated plateletlike nanoclay interfered with debonding of the polymer matrix. Therefore, it is considered that the tensile strength is increased overall. The tensile modulus of composites increased with the incorporation of fillers, and the highest value was found in W-WPC45/NC15/ GFC40 specimen (about $9961 \mathrm{MPa)}$ ). Since the nanoclay and glass fiber have a strong rigidity, the tensile modulus can be expected to be improved. However, as the amount of the fillers is increased, the aggregation of the fillers occurs and the dispersion does not occur properly. The interfacial bonding strength between the polymer matrix and the fillers is weakened and the 

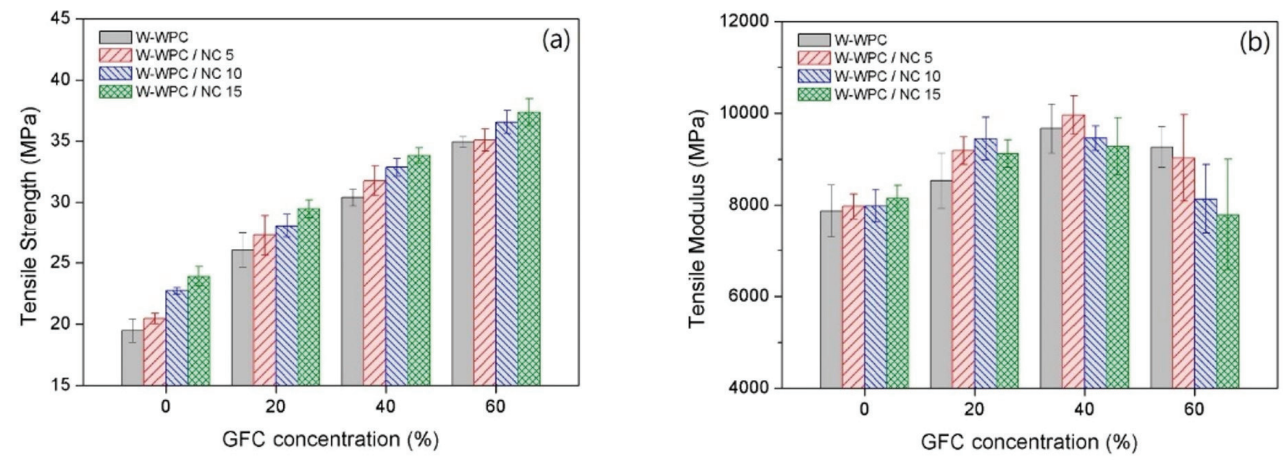

Fig. 5. Tensile properties of various recycled WPCs: (a) tensile strength (b) tensile modulus.
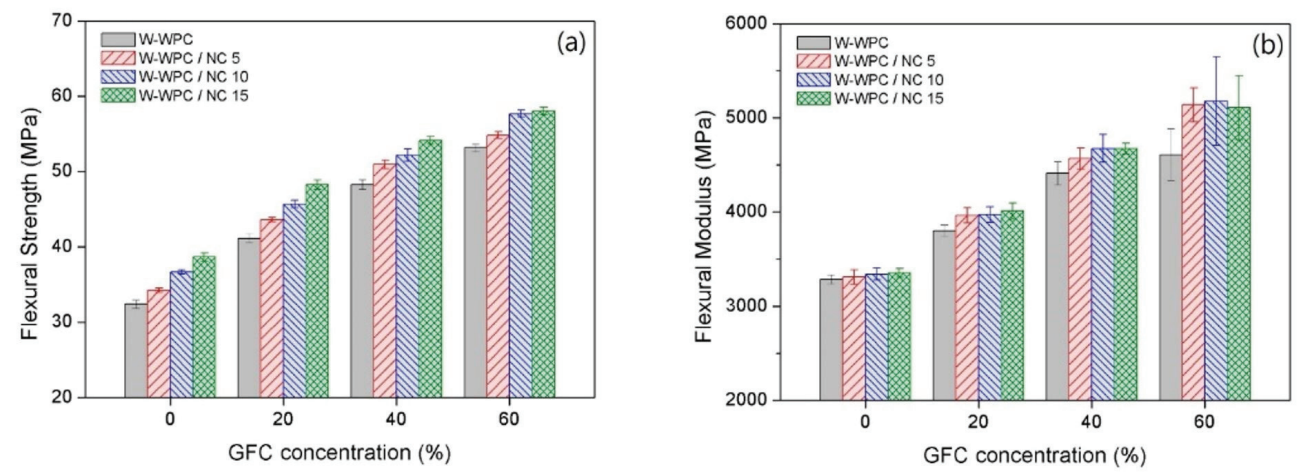

Fig. 6. Flexural properties of various recycled WPCs: (a) flexural strength (b) flexural modulus.

rigidity of the composites is reduced. The weakened rigidity of the composite means that the tensile modulus is decreased.

Flexural properties of various recycled WPCs are observed in Fig. 6. The incorporation of glass fiber and nanoclay in the composites improved the flexural strength. This result is similar to the above tensile strength result, and it is considered that the synergistic effect of the orientation of glass fiber in longitudinal direction and the platelet-like nanoclay shows improved flexural strength. It is also reported that the longer the glass fiber length, the higher the flexural strength (Thomasson, 2002). The flexural modulus increased with the incorporation of glass fiber. This is due to the fact that the orientation of glass fiber in longitudinal direction is increased and the rigidity of the glass fiber is stronger than that of other incorporated fillers. The flexural modulus is affected by the rigidity of incorporated fillers. The flexural modulus increased with the incorporation of $5 \mathrm{wt} . \% \mathrm{NC}$, but it showed no significant difference when incorporated more than 5 wt.\% NC. The flexural modulus can be increased due to the rigidity of the nanoclay as well. However, as the amount of nanoclay increases, aggregation occurs and it is not properly dispersed. Therefore, the interfacial bonding strength between polymer matrix and fillers is weakened and the flexural modulus decreases.

\subsection{Thermal properties}

Thermogravimetric (TG) and derivative thermogravi- 
Effects of Nanoclay and Glass Fiber on the Microstructural, Mechanical, Thermal, and Water Absorption Properties of Recycled WPCs

metric (DTG) curves of various recycled WPCs are observed in Fig. 7, Fig. 8, and Fig. 9. The total TGA results of composites are summarized in Table $3 . \mathrm{T}_{95}$ and $\mathrm{T}_{50}$ refer to the temperature at which remaining mass of the composites is 95 and $50 \%$, respectively.

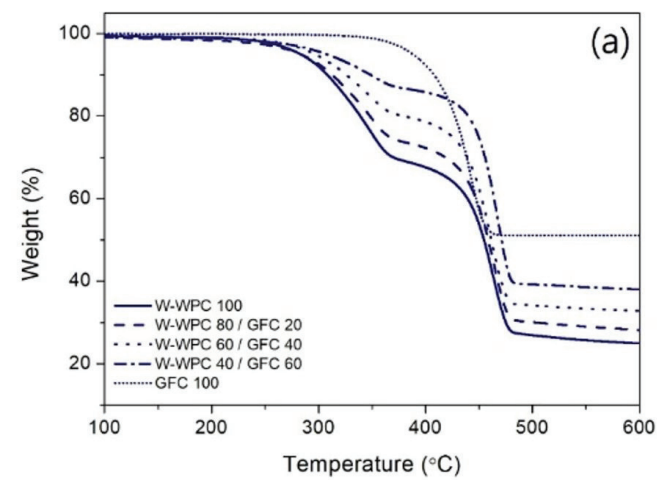

Fig. 7. TGA curves of various recycled WPCs (GFC series): (a) TG curve (b) DTG curve.
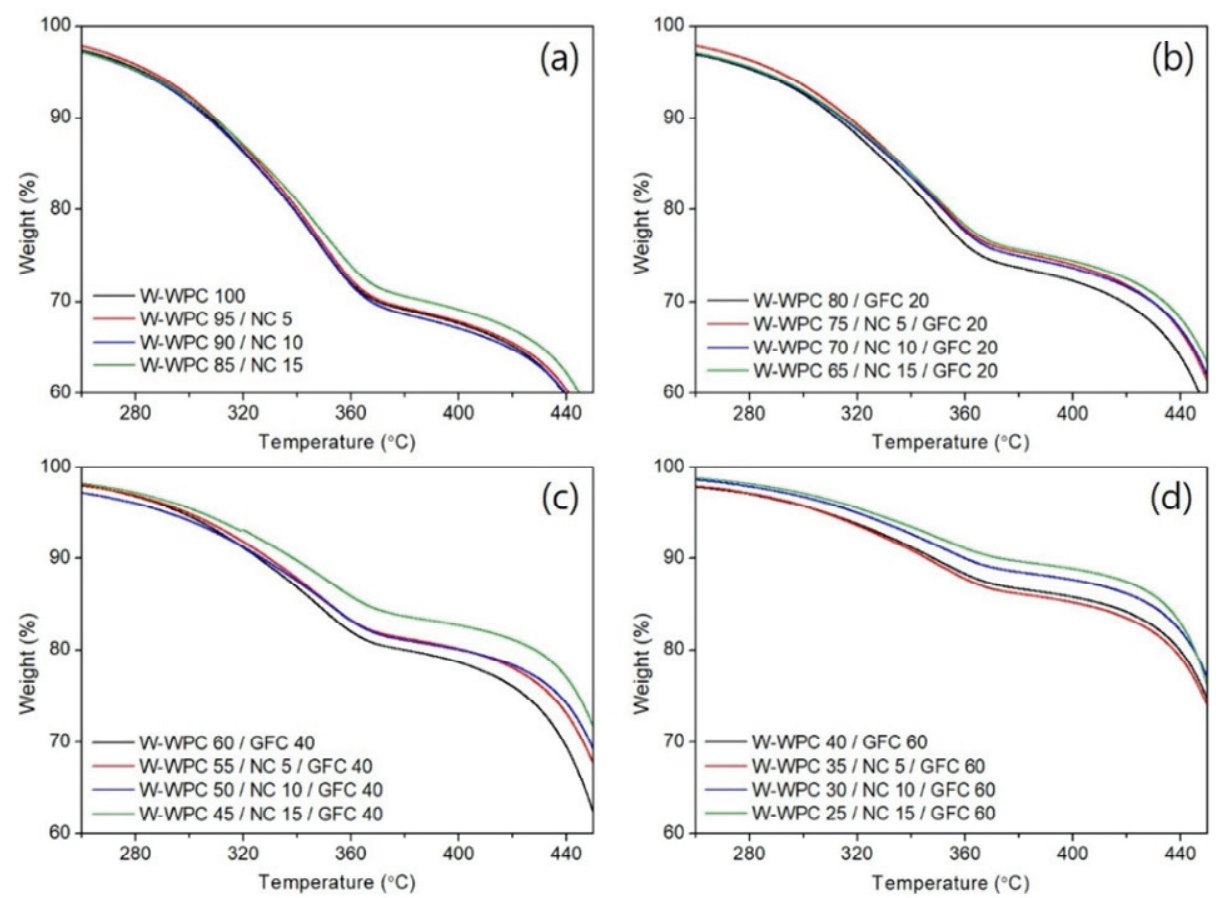

Fig. 8. TG curves of various recycled WPCs: (a) GFC 0 series (b) GFC 20 series (c) GFC 40 series (d) GFC 60 series.

The first and second stage peak maximum temperatures refer to $\mathrm{T}_{\text {peak }}{ }^{1}$ and $\mathrm{T}_{\text {peak }}{ }^{2}$, respectively. And the residue is the remaining amount after thermal decomposition. As the amount of waste WPCs decreased and the amount of fillers (glass fiber and nanoclay) increased, the TG

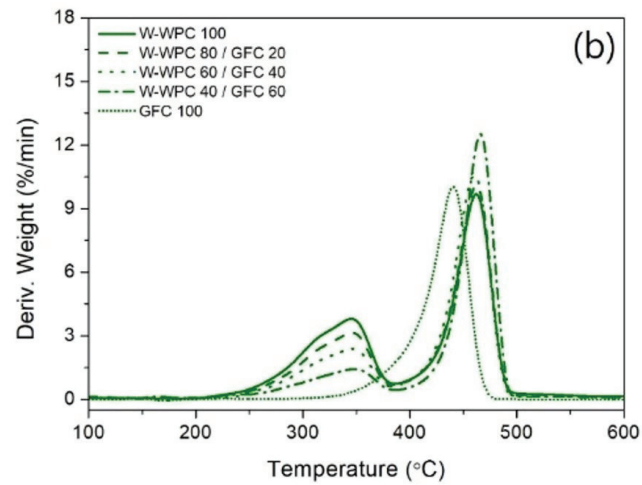



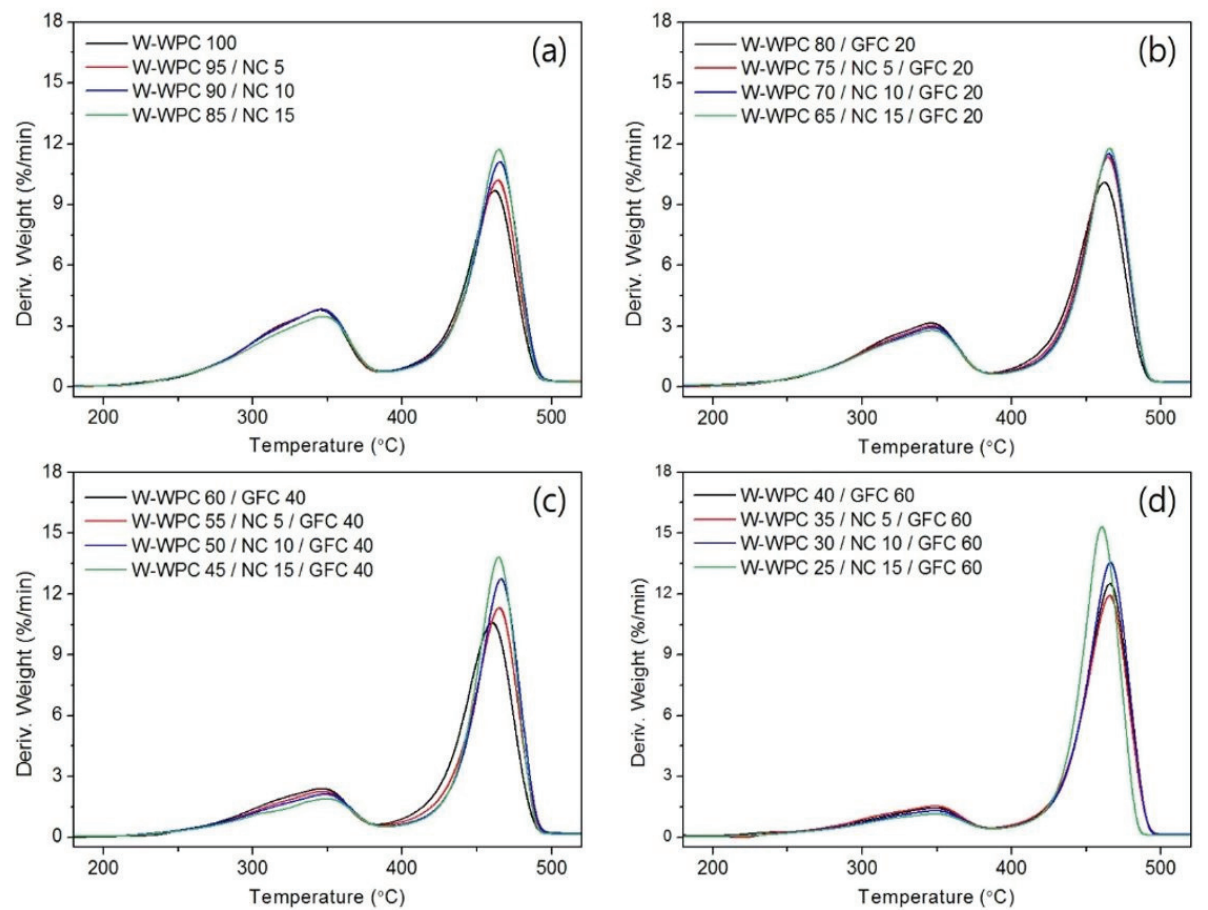

Fig. 9. DTG curves of various recycled WPCs: (a) GFC 0 series (b) GFC 20 series (c) GFC 40 series (d) GFC 60 series.

Table 3. TGA data of various recycled WPCs

\begin{tabular}{lccccc}
\hline \multicolumn{1}{c}{ Specimen } & $\begin{array}{c}\mathrm{T}_{95} \\
\left({ }^{\circ} \mathrm{C}\right)\end{array}$ & $\begin{array}{c}\mathrm{T}_{50} \\
\left({ }^{\circ} \mathrm{C}\right)\end{array}$ & $\begin{array}{c}\mathrm{T}_{\text {Peak }}{ }^{1} \\
\left({ }^{\circ} \mathrm{C}\right)\end{array}$ & $\begin{array}{c}\mathrm{T}_{\text {Peak }}{ }^{2} \\
\left({ }^{\circ} \mathrm{C}\right)\end{array}$ & $\begin{array}{c}\text { Residue } \\
(\%)\end{array}$ \\
\hline \hline W-WPC100 & 282.46 & 454.25 & 345.42 & 462.30 & 24.17 \\
W-WPC95/NC5 & 282.93 & 455.20 & 345.83 & 464.09 & 23.04 \\
W-WPC90/NC10 & 282.69 & 455.86 & 349.40 & 468.18 & 19.94 \\
W-WPC85/NC15 & 282.56 & 457.85 & 350.49 & 468.22 & 21.51 \\
\hline W-WPC80/GFC20 & 283.40 & 458.49 & 345.77 & 462.13 & 27.52 \\
W-WPC75/NC5/GFC20 & 284.81 & 461.79 & 346.14 & 464.65 & 26.69 \\
W-WPC70/NC10/GFC20 & 285.19 & 462.26 & 346.92 & 465.11 & 27.01 \\
W-WPC65/NC15/GFC20 & 285.28 & 463.67 & 347.05 & 465.55 & 27.91 \\
\hline W-WPC60/GFC40 & 294.22 & 461.31 & 346.36 & 460.29 & 32.26 \\
W-WPC55/NC5/GFC40 & 294.44 & 466.39 & 346.92 & 464.98 & 33.44 \\
W-WPC50/NC10/GFC40 & 295.08 & 466.96 & 348.15 & 466.23 & 31.09 \\
W-WPC45/NC15/GFC40 & 303.17 & 467.43 & 349.55 & 466.69 & 32.57 \\
\hline W-WPC40/GFC60 & 305.05 & 468.73 & 348.16 & 465.90 & 37.55 \\
W-WPC35/NC5/GFC60 & 305.89 & 468.94 & 348.44 & 465.69 & 38.48 \\
W-WPC30/NC10/GFC60 & 319.55 & 469.51 & 348.48 & 466.16 & 37.43 \\
W-WPC25/NC15/GFC60 & 324.35 & 469.90 & 349.22 & 466.95 & 38.53 \\
\hline GFC100 & - & - & - & 440.46 & 51.05 \\
\hline
\end{tabular}


Effects of Nanoclay and Glass Fiber on the Microstructural, Mechanical, Thermal, and Water Absorption Properties of Recycled WPCs

Table 4. DSC data of various recycled WPCs

\begin{tabular}{lccccccc}
\hline \multicolumn{1}{c}{ Specimen } & $\begin{array}{c}\mathrm{T}_{\mathrm{c}} \\
\left({ }^{\circ} \mathrm{C}\right)\end{array}$ & $\begin{array}{c}\mathrm{T}_{\mathrm{m}}{ }^{\circ} \\
\left({ }^{\circ} \mathrm{C}\right)\end{array}$ & $\begin{array}{c}\mathrm{T}_{\mathrm{m}}{ }^{2} \\
\left({ }^{\circ} \mathrm{C}\right)\end{array}$ & $\begin{array}{c}\triangle \mathrm{H}_{\mathrm{c}} \\
(\mathrm{J} / \mathrm{g})\end{array}$ & $\begin{array}{c}\triangle \mathrm{H}_{\mathrm{m}}{ }^{1} \\
(\mathrm{~J} / \mathrm{g})\end{array}$ & $\begin{array}{c}\triangle \mathrm{H}_{\mathrm{m}}{ }^{2} \\
(\mathrm{~J} / \mathrm{g})\end{array}$ & $\begin{array}{c}\mathrm{Xc}^{2} \\
(\%)\end{array}$ \\
\hline \hline W-WPC100 & 123.46 & 130.14 & 168.55 & 34.99 & 3.062 & 24.23 & 17.56 \\
W-WPC95/NC5 & 124.11 & 130.36 & 168.75 & 35.29 & 2.923 & 24.82 & 17.99 \\
W-WPC90/NC10 & 124.04 & 130.3 & 168.68 & 35.57 & 2.604 & 24.22 & 17.55 \\
W-WPC85/NC15 & 123.99 & 130.13 & 168.03 & 35.59 & 2.533 & 25.42 & 18.42 \\
\hline W-WPC80/GFC20 & 123.89 & 130.13 & 168 & 39.12 & 2.323 & 28.38 & 20.57 \\
W-WPC75/NC5/GFC20 & 124.28 & 130.08 & 167.94 & 37.6 & 2.06 & 27.68 & 20.06 \\
W-WPC70/NC10/GFC20 & 123.69 & 129.96 & 168.18 & 37.05 & 2.061 & 26.03 & 18.86 \\
W-WPC65/NC15/GFC20 & 125.37 & 129.85 & 167.69 & 41.48 & 1.918 & 30.24 & 21.91 \\
\hline W-WPC60/GFC40 & 123.84 & 129.91 & 168.08 & 40.96 & 1.418 & 30.78 & 22.30 \\
W-WPC55/NC5/GFC40 & 123.77 & 130.37 & 168.03 & 45.97 & 1.664 & 32.84 & 23.80 \\
W-WPC50/NC10/GFC40 & 124.58 & 130.6 & 168.44 & 43.05 & 1.444 & 32.44 & 23.51 \\
W-WPC45/NC15/GFC40 & 123.48 & 130.21 & 168.51 & 44.59 & 1.84 & 30.94 & 22.42 \\
\hline W-WPC40/GFC60 & 122.68 & 131.06 & 168.73 & 42.18 & 0.7422 & 31.71 & 22.98 \\
W-WPC35/NC5/GFC60 & 123.58 & 130.4 & 168.86 & 46.33 & 0.4243 & 34.17 & 24.76 \\
W-WPC30/NC10/GFC60 & 123.58 & 130.4 & 168.86 & 46.33 & 0.4243 & 34.17 & 24.76 \\
W-WPC25/NC15/GFC60 & 123.46 & 130.09 & 168.72 & 48.18 & 0.9368 & 35.36 & 25.62 \\
\hline GFC100 & 121.55 & - & 168.07 & 45.89 & - & 35.04 & 25.40 \\
\hline
\end{tabular}

curves of the composites shifted to the right and also the $T_{95}$ and $T_{50}$ values increased. This is because glass fiberis a filler with high heat resistance leading to the improvement of the thermal stability of the filled composites. In addition, the layered structure of nanoclay acts as a barrier to heat and delays the diffusion of volatile decomposition products in filled composites (Rahman et al., 2012; Choi et al., 2018). Therefore, it can be said that the hybrid composite incorporating nanoclay and glass fiber caused synergistic effect and improved the thermal stability of the composite. The DTG curves of composites shows two thermal degradation zones. While the $\mathrm{T}_{\text {peak }}{ }^{1}$ in the range of $345 \sim 349^{\circ} \mathrm{C}$ is associated with the thermal degradation of wood flour (particularly, cellulose), the $\mathrm{T}_{\text {peak }}{ }^{2}$ in the range of $462 \sim 466^{\circ} \mathrm{C}$ is related to the thermal degradation of polypropylene (Gwon et al., 2017). As the amount of waste WPCs decreased, the width of $\mathrm{T}_{\text {peak }}{ }^{1}$ decreased but the width of $\mathrm{T}_{\text {peak }}{ }^{2}$ increased. This is because thermal degra- dation of the composite is more affected by polypropylene than wood. The residues after thermal decomposition increased when glass fiber was incorporated, but showed no significant difference when nanoclay was incorporated. It is considered that this affects the residue values due to the various fillers and impurities present in the waste WPC.

The thermal characteristics by DSC are summarized in Table 4. $\mathrm{T}_{\mathrm{m}}{ }^{1}$ represents the melting point of polyethylene (PE) present in the waste WPCs and its enthalpy is represented by $\triangle H_{m}{ }^{1} \cdot T_{m}{ }^{2}$ represents the melting point of polypropylene (PP), and its enthalpy is represented by $\triangle \mathrm{H}_{\mathrm{m}}{ }^{2}$. Overall, $\mathrm{T}_{\mathrm{m}}{ }^{1}, \mathrm{~T}_{\mathrm{m}}{ }^{2}$, and $\mathrm{T}_{\mathrm{c}}$ showed no difference between composites. $\triangle \mathrm{H}_{\mathrm{m}}$ is an important parameter since its magnitude is directly proportional to the overall level of $\mathrm{X}_{\mathrm{c}}$ possessed by the polymer. NC and GFC used in this study are master-batches containing $50 \%$ of PP and $50 \%$ of fillers. As the amount of fillers (NC and GFC) increased, the 
amount of PP increased accordingly. As a result, the $\mathrm{X}_{\mathrm{c}}$ values were increased. This is because the presence of nanoclay in polymer matrix promotes nucleating effects and increases crystallization speed leading to increases $X_{c}$ values (Modesti et al., 2006). Also, the crystallization behavior of the composites is affected by amount and dispersion of fillers (Wang et al., 2002). Thereby, as the glass fiber and nanoclay were well dispersed in the composite, the hybrid filled composites showed the improvements of nucleating effect and $X_{c}$ value. In addition, as the amount of glass fiber and nanoclay fillers in the composite increased, the ratio of pure polypropylene accordingly (due to the use of master batch pellets) increased, which resulted in the increase of $\mathrm{X}_{\mathrm{c}}$ values.

\subsection{Water absorption properties}

The water absorption properties of various recycled WPCs are observed in Table 5 and Fig. 10. The GFC 100 composite having 50wt.\% glass fiber and 50wt.\% polypropylene showed nearly $0 \%$ water absorption and thickness swelling features. It can be seen that the glass fiber has little effect on the water absorption properties. For the recycled WPCs, as the amount of fillers (glass fiber and nanoclay) increases, the amount of waste
Table 5. Water absorption data of various recycled WPCs

\begin{tabular}{lcc}
\hline \multicolumn{1}{c}{ Specimen } & $\begin{array}{c}\text { Maximum } \\
\text { Water } \\
\text { Absorption (\%) }\end{array}$ & $\begin{array}{c}\text { Maximum } \\
\text { Thickness } \\
\text { Swelling (\%) }\end{array}$ \\
\hline \hline W-WPC100 & 12.740 & 7.509 \\
W-WPC95/NC5 & 11.317 & 7.316 \\
W-WPC90/NC10 & 8.370 & 7.003 \\
W-WPC85/NC15 & 6.248 & 6.617 \\
\hline W-WPC80/GFC20 & 10.050 & 6.676 \\
W-WPC75/NC5/GFC20 & 8.057 & 6.374 \\
W-WPC70/NC10/GFC20 & 8.764 & 5.479 \\
W-WPC65/NC15/GFC20 & 6.365 & 4.706 \\
\hline W-WPC60/GFC40 & 6.426 & 4.988 \\
W-WPC55/NC5/GFC40 & 4.726 & 4.257 \\
W-WPC50/NC10/GFC40 & 3.148 & 3.489 \\
W-WPC45/NC15/GFC40 & 2.467 & 3.276 \\
\hline W-WPC40/GFC60 & 4.835 & 3.602 \\
W-WPC35/NC5/GFC60 & 2.483 & 2.962 \\
W-WPC30/NC10/GFC60 & 2.090 & 2.769 \\
W-WPC25/NC15/GFC60 & 1.391 & 2.406 \\
\hline GFC100 & 0.102 & 0.622 \\
\hline
\end{tabular}

WPCs decreases. This means that the absolute amount of wood flour is reduced. Wood flour has a hydrophilic hydroxyl group and it is less affected by water absorption as the wood flour content decreases (Ayrilmis et
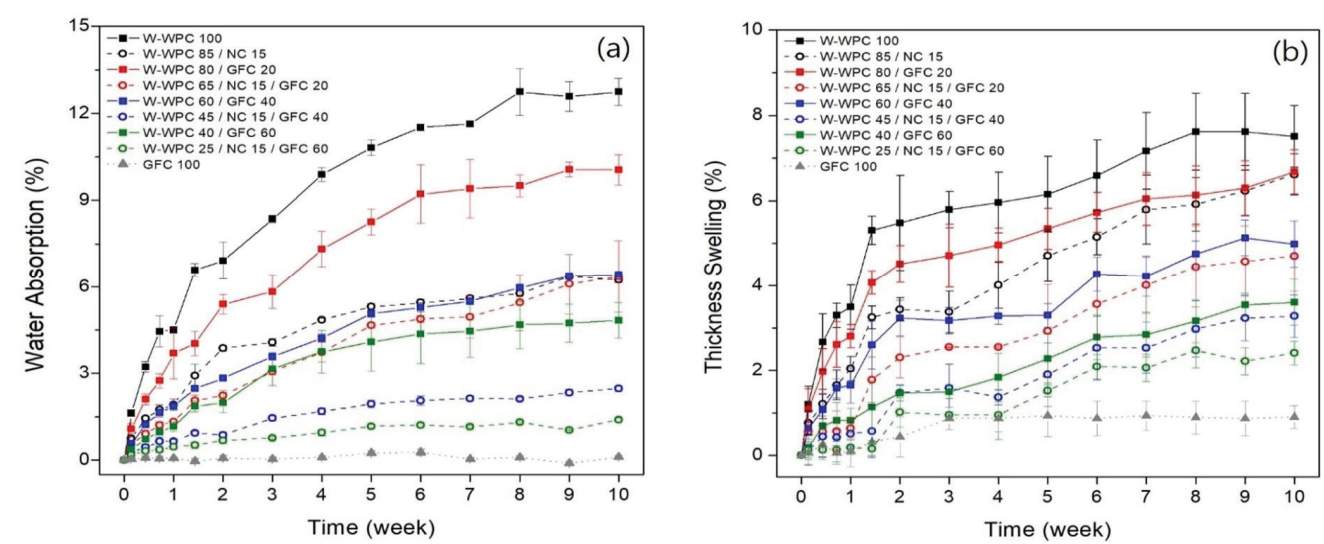

Fig. 10. Water absorption properties of various recycled WPCs: (a) water absorption (b) thickness swelling. 
Effects of Nanoclay and Glass Fiber on the Microstructural, Mechanical, Thermal, and Water Absorption Properties of Recycled WPCs

al., 2012). However, even if the amount of wood flour is reduced, the recycled WPCs with glass fiber only (W-WPC80/GFC20, W-WPC60/GFC40, and W-WPC40/ GFC60) showed higher water absorption properties than the composites with both nanoclay and glass fiber (W-WPC85/NC15, W-WPC65/NC15/GFC20, and WWPC45/NC15/GFC40). This is because the nanoclay in the composites interferes with the diffusion path of water molecules to the interior, thereby acting as a barrier to prevent water absorption (Alamri et al., 2012). Due to this reason, water molecules were delayed in reaching the inner part of the composite. Similar trends were observed in thickness swelling properties as well. This suggests that the presence of nanoclay in the composites prevents the expansion of thickness caused by water and gives a dimensional stability to the composites.

\section{CONCLUSION}

In this study, the effects of glass fiber and nanoclay on the microstructural, mechanical, thermal, and water absorption properties of various recycled WPCs based on waste WPC which is used for a certain period of time.

The XRD patterns properly confirmed the intercalation of nanoclay present in hybrid recycled WPCs reinforced with nanoclay and glass fiber. The SEM images showed that nanoclay and glass fiber were properly dispersed in recycled WPCs and good interfacial bondings between fillers and plastic matrix were observed. The incorporation of nanoclay and glass fiber improved the tensile and flexural strength of recycled WPCs. However, as the content of nanoclay increased, the impact strength decreased. The highest value of tensile modulus was observed in W-WPC55/ NC5/GFC40 specimen, but further increase of filler contents led to decreased tensile modulus. For flexural modulus, it was not improved with increasing nanoclay content. This indicates that the incorporation of large amounts of fillers into composite made it difficult to improve the modulus by aggregation of the fillers. TG and DTG analyses showed that the hybrid incorporation of nanoclay and glass fiber into composite led to synergistic effect and gave thermal stability to recycled WPCs. Also, the fillers promoted nucleation effect and improved the crystallinity $\left(\mathrm{X}_{\mathrm{c}}\right)$ of the recycled WPCs. The presence of nanoclay in recycled WPCs resulted in the delayed effect on the water absorption and thickness swelling properties by acting as a barrier. Our results suggest that hybrid recycled WPCs reinforced with nanoclay and glass fiber are highly applicable for recycling of waste WPCs.

\section{ACKNOWLEDGMENT}

This research was conducted with the financial support of the National Institute of Forest Science (Project No. A2018-0113).

\section{REFERENCES}

Adhikary, K.B., Pang, S., Staiger, M.P. 2008. Dimensional stability and mechanical behavior of wood-plastic composites based on recycled and virgin high-density polyethylene(HDPE). Composites Part B: Engineering 39(5): 807-815.

Alamri, H., Low, I.M. 2012. Effect of water absorption on the mechanical properties of nano-filler reinforced epoxy nanocomposites. Materials \& Design 42: 214-222.

Ashori, A. 2008. Wood-plastic composites as promising green-composites for automotive industries!. Bioresource Technology 99(11): 4661-4667.

Ayrilmis, N., Akbulut, T., Dundar, T., White, R.H., Mengeloglu, F., Buyuksari, U., Candan, Z., Avci, E. 2012. Effect of boron and phosphate compounds on physical, mechanical, and fire properties of 
wood-polypropylene composites. Construction and Building Materials 33: 63-69.

Borse, N.K., Kamal, M.R. 2009. Estimation of stresses required for exfoliation of clay particles in polymer nanocomposites. Polymer Engineering and Science 49(4): 641-650.

Bozkurt, E., Kaya, E., Tanoglu, M. 2007. Mechanical and thermal behavior of non-crimp glass fiber reinforced layered clay/epoxy nanocomposites. Composites Science and Technology 67(15-16): 3394-3403.

Chaharmahali, M., Tajvidi, M. 2008. Mechanical properties of wood plastic composite panels made from waste fiberboard and particleboard. Polymer Composites 29(6): 606-610.

Choi, Y.S., Park, J.W., Lee, J.H., Shin, J.H., Jang, S.W., Kim, H.J. 2018. Preparation of EVA/intumescent/ nano-clay composites with flame retardant properties and cross laminated timber (CLT) application technology. Journal of the Korean Wood Science and Technology 46(1): 73-84.

Deka, B.K., Maji, T.K. 2010. Effect of coupling agent and nanoclay on properties of HDPE, LDPE, PP, PVC blend and Phargamites karka nanocomposite. Composites Science and Technology 70(12): 17551761.

Gardner, D.J., Han, Y., Wang, L. 2015. Wood-plastic composite technology. Wood Structure and Function 1(3): 139-150.

Gwon, J.G., Lee, D.B., Cho, H.J., Chun, S.J., Choi, D.H., Lee, S.Y. 2017. Determination on wood flour content in WPC through thermogravimetric analysis and accelerator mass spectrometry. Journal of the Korean Wood Science and Technology 45(5): 572579.

Hemmasi, A.H., Khademi-Eslam, H., Talaiepoor, M., Kord, B. 2010. Effect of nanoclay on the mechanical and morphological properties of wood polymer nanocomposite. Journal of Reinforced Plastics and
Composites 29(7): 964-971.

Hyvarinen, M., Ronkanen, M., Karki, T. 2019. The effect of the use of construction and demolition waste on the mechanical and moisture properties of a wood-plastic composite. Composite Structure 210: 321-326.

Jiang, H., Kamdem, D.P., Bezubic, B., Ruede, P. 2003. Mechanical properties of poly(vinyl chloride)/wood flour/glass fiber hybrid composites. Journal of Vinyl \& Additive Technology 9(3): 138-145.

Kanny, K., Jawahar, P., Moodley, V.K. 2008. Mechanical and tribological behavior of clay-polypropylene nanocomposites. Journal of Materials Science 43(22): 7230-7238.

Kim, B.C., Park, S.W., Lee, D.G. 2008. Fracture toughness of the nano-particle reinforced epoxy composite. Composite Structures 86(1-3): 69-77.

Kim, B.J. 2014. Overview of wood plastic composites: focusing on use of bio-based plastics and coextrusion technique. Journal of the Korean Wood Science and Technology 42(5): 499-509.

Modesti, M., Lorenzetti, A., Bon, D., Besco, S. 2006. Thermal behaviour of compatibilised polypropylene nanocomposite: Effect of processing conditions. Polymer Degradation and Stability 91(4): 672-680.

Najafi, S.K., Hamidinia, E., Tajvidi, M. 2006. Mechanical properties of composites from sawdust and recycled plastics. Journal of Applied Polymer Science 100(5): 3641-3645.

Pinnavaia, T.J., Beall, G.W. 2000. Polymer-clay nanocomposites. John Wiley.

Rahman, N.A., Hassan, A., Yahya, R., Lafia-Araga, R.A., Hornsby, P.R. 2012. Micro-structural, thermal, and mechanical properties of injection-molded glass fiber/nanoclay/polypropylene composites. Journal of Reinforced Plastics and Composites 31(4): 269-281.

Rahman, N.A., Hassan, A., Yahya, R. 2012. Polypropylene/ glass fiber/nanoclay hybrid composites: morpho- 
Effects of Nanoclay and Glass Fiber on the Microstructural, Mechanical, Thermal, and Water Absorption Properties of Recycled WPCs

logical, thermal, dynamic mechanical and impact behaviors. Journal of Reinforced Plastics and Composites 31(18): 1247-1257.

Rizvi, G.M., Semeralul, H. 2008. Glass-fiber-reinforced wood/plastic composites. Journal of Vinyl \& Additive Technology 14(1): 39-42.

Thomason, J.L. 2002. The influence of fibre length and concentration on the properties of glass fibre reinforced polypropylene: 5. Injection moulded long and short fibre PP. Composites Part A: Applied Science and Manufacturing 33(12): 1641-1652.
Wang, K.H., Choi, M.H., Koo, C.M., Xu, M., Chung, I.J., Jang, M.C., Choi, S.W., Song, H.H. 2002. Morphology and physical properties of polyethylene/ silicate nanocomposite prepared by melt intercalation. Journal of Polymer Science: Part B: Polymer Physics 40(14): 1454-1463.

Zhang, Y., Ma, Y. 2016. Study on the preparation and mechanical properties of fiberglass reinforced wood-based composite. Journal of the Korean Wood Science and Technology 44(4): 505-514. 